\title{
Role for Calcium from the Sarcoplasmic Reticulum in Coupling Muscle Activity to Nicotinic Acetylcholine Receptor Gene Expression in Rat
}

\author{
Larry Adams, Daniel Goldman \\ Mental Health Research Institute and Department of Biological Chemistry, 205 Zina Pitcher Place, \\ University of Michigan, Ann Arbor, Michigan 48109
}

Received 12 September 1997; accepted 29 December 1997

\begin{abstract}
Neurally evoked muscle electrical activity suppresses nicotinic acetylcholine receptor ( $\mathrm{nAChR}$ ) gene expression in extrajunctional domains of adult muscle fibers. It has been proposed that this regulation is mediated by calcium influx through voltage-dependent L-type calcium channels but bypasses the sarcoplasmic reticulum in chick and mouse $\mathrm{C2C12}$ cells. Here we report that in rat muscle calcium influx through L-type calcium channels preferentially reduced nAChR $\varepsilon$-subunit RNA via a post-transcriptional mechanism. In contrast, calcium release from the sarcoplasmic reticulum (SR) suppressed $\mathrm{nAChR}$
\end{abstract}

subunit RNA levels as a result of decreasing nAChR subunit promoter activity. Finally, we show that this decreased promoter activity is mediated through the same DNA sequences that control activity-dependent gene expression. Therefore, we propose that in rat muscle, calcium release from the $S R$ participates in coupling muscle depolarization to $\mathrm{AAChR}$ gene expression. (C) 1998 John Wiley \& Sons, Inc. J Neurobiol 35: 245257, 1998

Keywords: muscle; nicotinic acetylcholine receptor; activity-dependent gene expression; calcium; sarcoplasmic reticulum

\section{INTRODUCTION}

Synaptogenesis at the neuromuscular junction (NMJ) serves as an excellent system for studying how the presynaptic neuron can control postsynaptic gene expression. For example, muscle innervation results in the repression of $\mathrm{nAChR}$ genes $(\alpha \beta \gamma \delta)$ in extrajunctional myonuclei and the induction of $\mathrm{nAChR}$ genes $(\alpha \beta \varepsilon \delta)$ in endplate-associated myonuclei (Klarsfeld et al., 1991; Sanes et al., 1991; Simon et al., 1992; Gundersen et al., 1993; Hall and Sans, 1993). This latter induction seems to be mediated by nerve-derived ARIA (Sandrock et al., 1977), a neuregulin (Falls et al., 1993), that binds epidermal growth factor (EGF)-like receptors (Moscoso et

\footnotetext{
Correspondence to: D. Goldman

Contract grant sponsor: NIH

Contract grant sponsor: Muscular Dystrophy Association (C) 1998 John Wiley \& Sons, Inc. CCC 0022-3034/98/030245-13
}

al., 1995; Altiok et al., 1995; Zhu et al., 1995), while the extrajunctional suppression of nAChR gene expression is mediated by nerve-induced muscle depolarization (Simon et al., 1992; Klarsfeld and Changeux, 1985; Goldman et al., 1988).

The molecular mechanism by which muscle activity suppresses nAChR gene expression is not well understood. However, it has been suspected that components of the signaling cascade that mediates excitation-contraction coupling may also participate in coupling membrane depolarization to nAChR gene expression. Although early reports suggested that calcium released from the sarcoplasmic reticulum (SR) can suppress $\mathrm{nAChR}$ protein levels (Birnbaum et al., 1980; Pezzementi and Schmidt, 1981), more recent experiments suggest that calcium influx across the plasma membrane, through L-type channels, may be responsible for decreasing $\mathrm{nAChR}$ gene expression in response to muscle activity (Klarsfeld et al., 1989; Huang and 
Schmidt, 1994; Huang et al., 1994). This result suggests that DNA sequences mediating activity-dependent gene expression should also mediate the effects of calcium influx. Surprisingly, this was never tested.

Therefore, we examined the effect various calcium-perturbing drugs had on nAChR RNA levels and promoter activity in primary rat muscle cultures. In contrast to that reported for chick muscle (Huang et al., 1994; Huang and Schmidt, 1994), calcium influx through L-type channels preferentially reduced rat nAChR $\varepsilon$-RNA via a post-transcriptional mechanism. However, calcium release from the SR decreased all $n A C h R$ subunit RNAs by decreasing transcription from their promoters. Most important, we show that these drugs mediate their effects by acting through the same DNA elements previously shown to mediate activity-dependent control of gene expression. Taken together, these results suggest that in rat, muscle activity mediates its effects on nAChR gene expression, at least in part, by stimulating calcium release from the SR. Although in contradiction to some recent work (Huang and Schmidt, 1994; Huang et al., 1994), these results are consistent with older reports suggesting SR calcium regulates nAChR protein levels (Birnbaum et al., 1980; Pezzementi and Schmidt, 1981; Forrest et al., 1981).

\section{MATERIALS AND METHODS}

\section{RNA Isolation and RNase Protection Assay}

Total RNA was isolated using the method of Chirgwin et al. (1979). Antisense RNA probes used to detect muscle creatine kinase (MCK) and $\mathrm{nAChR} \alpha, \beta, \gamma, \delta$, and $\varepsilon$ RNAs were described previously (Chahine et al., 1993). RNase protection assays were carried out as previously described (Walk et al., 1994; Saccomanno et al., 1992). The MCK probe was included in every RNase protection assay and served to normalize for different amounts of RNA in the various samples. The MCK RNA also serves to indicate if the cellular perturbations we imposed on the cultured muscle cells had a general effect on myogenic factor activity, since the MCK RNA is induced by myogenic factors upon muscle differentiation in a similar fashion as the nAChR genes. MCK RNA was not regulated by any of the conditions employed in this report. RNase protection assays were repeated at least twice and quantitated by scanning densitometry. Specificity of protected bands was confirmed by hybridizing probes to tRNA, which resulted in no protected fragments on the gel. In addition, probe integrity was monitored by omitting the RNase step during the RNase protection protocol.

\section{Cell Culture}

Rat primary muscle cells were isolated and cultured as described previously (Chahine et al., 1993). Cells were plated on 60-mm collagen-coated culture dishes at a density of $3 \times 10^{6}$ cells $/ \mathrm{mL}$. In general, these cells began to fuse by day 4 postplating and plates became confluent with contracting myotubes around day 6 . At this time, cells were maintained in medium containing tetrodotoxin ( $3 \mu \mathrm{g} / \mathrm{mL}$ ) to prevent myotube contraction. Cells were transfected on day 6 postplating and were treated with various calcium-perturbing drugs about $48 \mathrm{~h}$ later. Cultures were also treated with cytosine arabinoside $(3 \mu \mathrm{g} /$ $\mathrm{mL}$ ) for $24-48 \mathrm{~h}$ beginning immediately after transfection. Cells for RNase protection were treated with drugs on day 8 postplating. Control cells were treated with vehicle used to dissolve the drug.

\section{Expression Vectors and Transfection Assays}

The chick nAChR 850 bp $\alpha$-subunit promoter was kindly provided by J. P. Merlie (Merlie and Kornhauser, 1989). This DNA was digested with BglI, blunted, and then digested with HindIII to release a 116-bp $\alpha$-promoter fragment that was subcloned into SmaI/HindIII-digested pXP1 (Nordeen, 1988). This generates an expression vector harboring an $\alpha$-promoter fragment spanning nucleotides -116 to +20 driving luciferase expression. The $\alpha$-subunit promoter mutants $\mathrm{Mp}$ and $\mathrm{Mb}$ have been previously described (Piette et al., 1990). Mutations were created by site-directed mutagenesis using oligonucleotide primers and confirmed by DNA sequencing. The CMVCAT, mouse $\gamma$-, and rat $\delta$ - and $\varepsilon$-promoter/luciferase expression vectors have been previously described (Gilmour et al., 1995; Walke et al., 1994, 1996). The rat $\delta$-promoter expression vector is a chimera containing the rat $\delta$-promoter's 47-bp activity-dependent enhancer upstream the minimal enkephalin (MEK) promoter (Walke et al., 1996). This construct is more active than that lacking the MEK sequences. The MEK promoter was not regulated by calcium (Walke et al., 1994). CMVCAT was not influenced by ryanodine or $(-)$ Bay K 8644 in our muscle culture system (CAT activity ratio for ryanodine/control was $0.99 \pm 0.12$ averaged over 30 experiments; CAT activity ratio for Bay K 8644/control was $1.1 \pm 0.12$ averaged over seven experiments ) and therefore used for normalization purposes. Myotube cultures were transfected using calcium phosphate DNA precipitates as previously described by Chahine et al. (1992). CMVCAT was used at $3 \mu \mathrm{g} /$ plate and the various $\mathrm{nAChR}$ wild-type and mutant expression vectors were used at $10-20 \mu \mathrm{g} /$ plate. Total DNA was adjusted to $30 \mu \mathrm{g} /$ plate using BSSK $(+)$ (Stratagene) DNA. Luciferase and CAT assays were performed as previously described (Brasier et al., 1989; Neumann et al., 1987). Experiments were performed in triplicate and repeated at least twice. 


\section{Drugs and Reagents}

Ryanodine, thapsigargin, dantrolene, and the $(+)$ and ( - ) enantiomers of Bay K 8644 were purchased from RBI (Natick, MA). A23187 was obtained from Sigma (St. Louis, MO). Tetrodotoxin was purchased from Molecular Probes (Eugene, OR). Ryanodine was prepared fresh as either a $1-$ or $10-\mathrm{m} M$ stock as described previously (Pezzementi and Schmidt, 1981). Dantrolene and the $(+)$ and $(-)$ enantiamers of Bay K 8644 were prepared as $10-\mathrm{m} M$ stocks in dimethyl sulfoxide (DMSO). Thapsigargin and A23187 were prepared as 1-m $M$ stocks in DMSO.

\section{RESULTS}

\section{Calcium-Dependent Regulation of nAChR RNA Levels}

To determine if calcium influx across the plasma membrane and/or efflux from the SR could regulate nAChR expression, we assayed nAChR RNA levels in rat primary myotube cultures treated with various calcium-perturbing pharmacological reagents. Ryanodine and thapsigargin increases calcium efflux from the SR by activating the ryanodine receptor (Meissner, 1968; Buck, 1992) and inhibiting SR calcium transport ATPase activity (Sagara and Inesi, 1991), respectively. In contrast, Bay K 8644 specifically acts on L-type calcium channels that control calcium influx across the plasma membrane (Smilowitz, 1988; Reuter et al., 1985). We also used the calcium ionophore A23187, which is expected to equilibrate calcium across all membranes.

Similar to previously published results (Walke et al., 1994), we found A23187 suppressed expression of all five nAChR subunit RNAs (Fig. 1). For the $\varepsilon$-RNA, we had previously shown that A23187mediated suppression required calcium influx from extracellular stores (Walke et al., 1994). By using the L-type calcium channel agonist (-)Bay K 8644 , we confirmed this result and showed that $\varepsilon$ RNA levels decreased approximately $75 \%$ by calcium influx across the plasma membrane (Fig. 1). In contrast, $(-)$ Bay K 8644 had no effect on $\beta$ - or $\gamma$-RNA levels and reduced $\alpha$ - and $\delta$-RNA levels only by about $20 \%$ and $40 \%$, respectively (Fig. 1).

In contrast to the relatively specific and dramatic action of (-) Bay K 8644 on the $\varepsilon$-RNA, ryanodine and thapsigargin caused a decrease in all the $\mathrm{nAChR}$ RNAs (Fig. 1). The degree of repression varied from about $75-88 \%$ for the $\alpha$ - and $\gamma$-RNAs to approximately $50 \%$ for the $\beta$ - and $\delta$-RNAs. Interestingly the $\varepsilon$-RNA was least responsive to these drugs
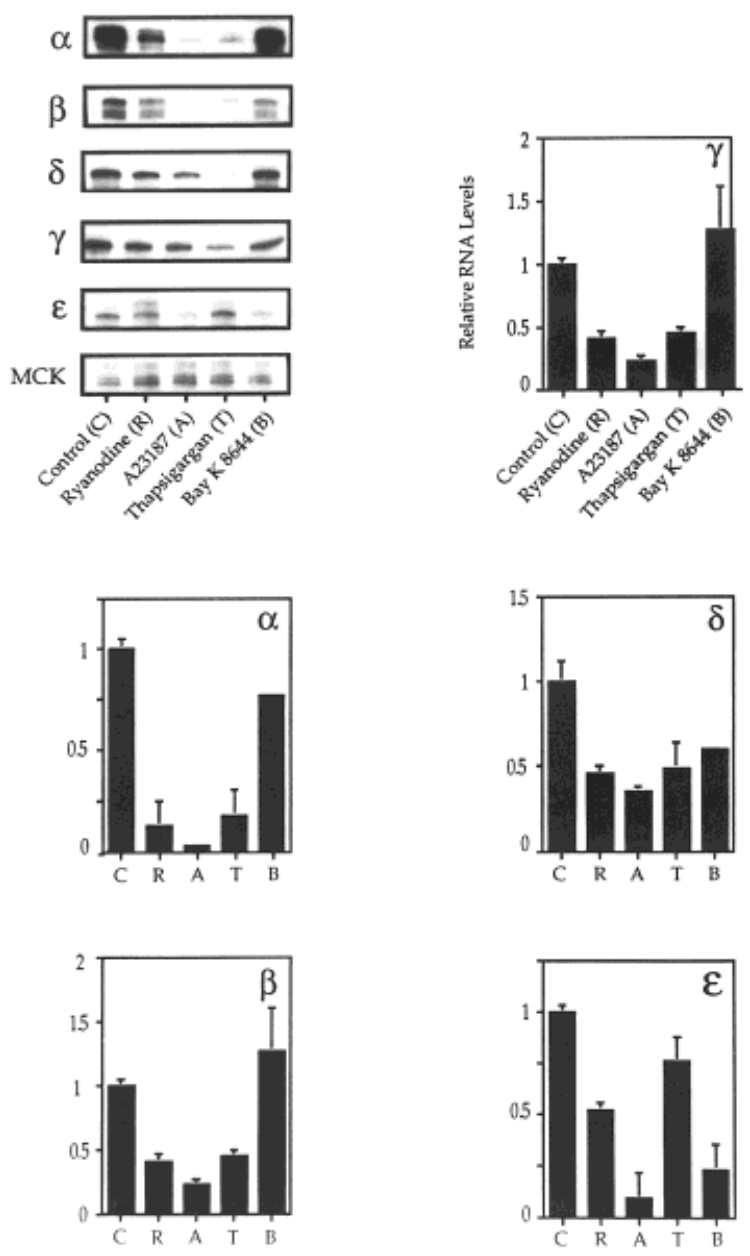

Figure 1 Calcium-dependent regulation of $\mathrm{nAChR}$ RNA levels. Primary myotubes were treated with either 1.0 $\mu M$ ryanodine, $150 \mathrm{n} M$ thapsigargan, $20.0 \mu M$ Bay $\mathrm{K} 8644$, or $1.0 \mu M \mathrm{~A} 23187$ for $48 \mathrm{~h}$ prior to harvesting cells and isolating RNA. Muscle $\mathrm{nAChR}$ and creatine kinase (MCK) RNA levels were revealed by RNase protection assays. (Top left) Typical RNase protection assay. The graphs are quantitation of multiple RNase protection assays. Quantitation of RNase resistant hybrids was performed by scanning densitometry. nAChR RNA levels were normalized to MCK RNA levels to correct for different RNA yields between the different samples. RNase protection assays were repeated at least twice with different samples of muscle RNA. Error bars are \pm standard deviation.

(ryanodine and thapsigargin) and was reduced by only $25-45 \%$. We have assayed the response of the $\alpha$-subunit RNA to $1 \mu M$ ryanodine in over 10 independent experiments. Although ryanodine generally causes a $75-85 \%$ decrease (Figs. 1 and 2; see also Fig. 4) in $\alpha$-RNA levels, we observed effects as small as $60 \%$ (see Fig. 7). Although we do not know the reason for this variability, it may reflect 

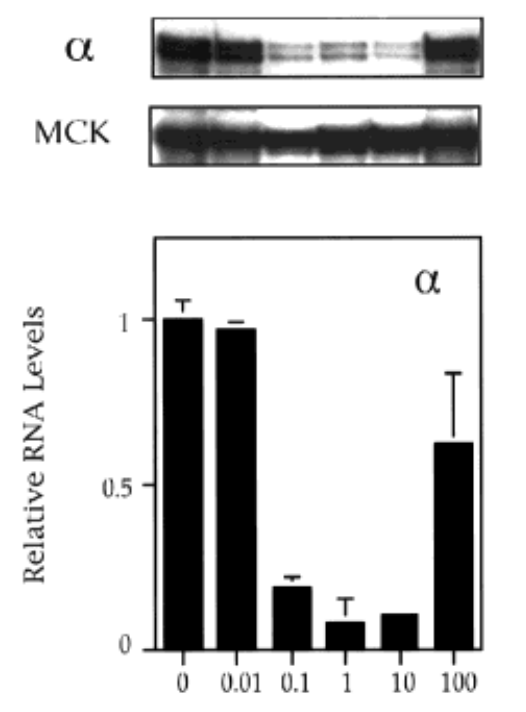

Ryanodine $(\mu \mathrm{M})$
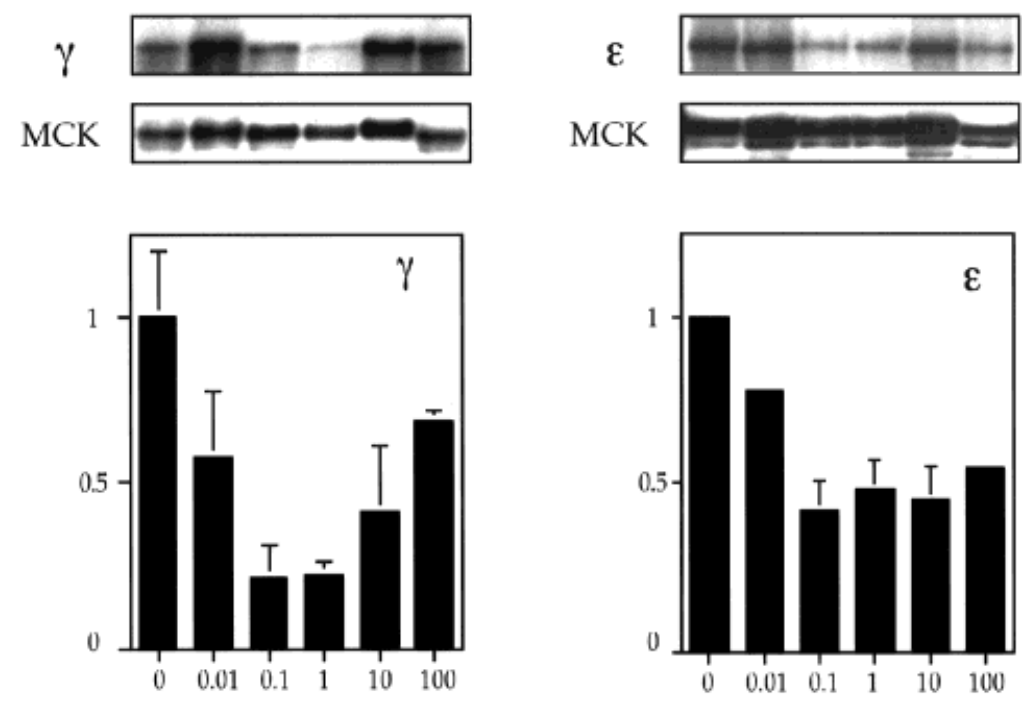

Ryanodine $(\mu \mathrm{M})$

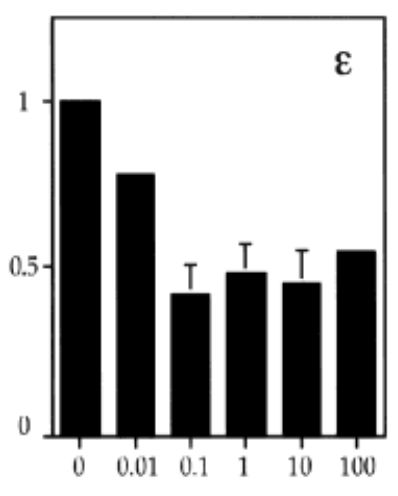

Ryanodine ( $\mu \mathrm{M})$

Figure 2 Concentration-dependent effect of ryanodine on nAChR RNA levels. Primary myotubes were treated with various concentrations of ryanodine for $48 \mathrm{~h}$ prior to harvesting cells and isolating RNA. Muscle nAChR $\alpha-, \varepsilon^{-}$, and $\gamma$-subunits and creatine kinase (MCK) RNA levels were revealed by RNase protection assays. (Top) Representative RNase protection assays. (Bottom) Quantitation of RNase protection assays. Relative RNA levels were determined by scanning densitometry and dividing nAChR RNA values by MCK RNA values (see Materials and Methods). RNase protection assays were repeated at least twice with different samples of muscle RNA. Error bars are \pm standard deviation.

slight variations in our ryanodine stock solution and/or the developmental stage of our primary muscle cultures. These changes in nAChR RNA levels in response to ryanodine and thapsigargin are similar to those previously documented for active and inactive myotubes (Chahine et al., 1993).

Ryanodine is unusual in that it stimulates calcium release from the SR at concentrations around $0.1-$ $10 \mu M$ and begins to block the release of SR calcium at concentrations above $10 \mu M$ (Meissner, 1968; Buck et al., 1992; Delbono and Chu, 1995). This concentration-dependent effect of ryanodine on calcium release was also reflected in $\alpha$ - and $\gamma$ RNA levels (Fig. 2). In contrast, the $\varepsilon$-RNA responded similarly to low $(1-\mu M)$ and high (100$\mu M$ ) concentrations of ryanodine (Fig. 2), which may indicate a nonspecific effect on this RNA. Nonetheless, these experiments and others (Fig. 1) consistently revealed that ryanodine was less effective at reducing $\varepsilon$-RNA levels compared to the other nAChR RNAs.

\section{Calcium Release from the SR Suppresses nAChR Gene Expression}

Transient transfection assays were used to examine the effect of ryanodine on $\mathrm{nAChR}$ promoter activity.
Forty-eight-hour exposure to ryanodine resulted in a concentration-dependent decrease in nAChR promoter activity (data shown for the 116-bp $\alpha$-promoter) (Fig. 3), similar to the response of the endogenous RNA. Maximal inhibition was observed at $1 \mu M$ ryanodine, which decreased $\alpha$-promoter activity by approximately $66 \%$, while $100 \mu M$ ryanodine had little effect (Fig. 3 ). Also, $1 \mu M$ ryanodine suppressed expression from the 388-bp $\gamma$-promoter (63\% reduction), 102-bp $\delta$-promoter (72\% reduction), and $5-\mathrm{kb} \varepsilon$-promoter (69\% reduction).

Within $6 \mathrm{~h}$ following exposure to $1 \mu M$ ryanodine, the $\alpha$-promoter was already suppressed approximately $50 \%$ (Fig. 4, bottom). However, we did not detect a significant decrease in $\alpha$-RNA until $12 \mathrm{~h}$ after drug treatment (Fig. 4, top). These results are not surprising since transcriptional changes usually precede changes in RNA levels which are governed by both transcription and stability.

In contrast to ryanodine, (-)Bay K 8644 had only a small effect on nAChR $\alpha$-promoter activity, resulting in approximately a $20-25 \%$ decrease after $48 \mathrm{~h}$ (Fig. 5, top). In addition, none of the other $\mathrm{nAChR}$ promoters were regulated by $(-)$ Bay $\mathrm{K}$ 8644 at concentrations ranging from 1 to $30 \mu M$ (data only shown for the $\varepsilon$-promoter) (Fig. 5, bot- 


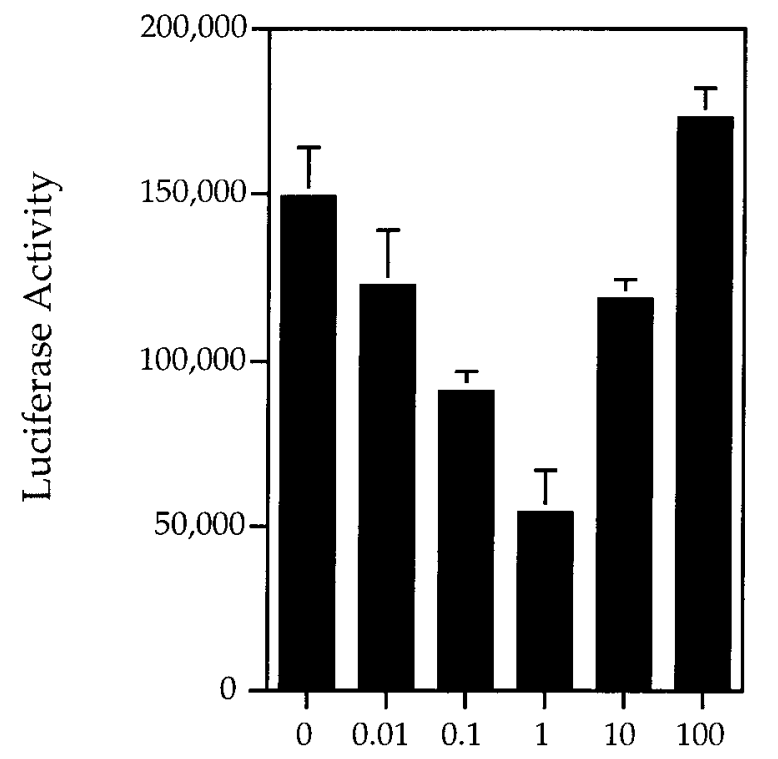

\section{Ryanodine $(\mu \mathrm{M})$}

Figure 3 Concentration-dependent effect of ryanodine on nAChR $\alpha$-subunit promoter activity. Primary muscle cultures were cotransfected with a 116-bp chick $\alpha$-promoter/luciferase expression vector and CMVCAT. Transfected cells were treated with varying concentrations of ryanodine for $48 \mathrm{~h}$ prior to harvesting and assaying reporter gene expression. The CMVCAT vector is not regulated by ryanodine and was used for normalization purposes. Bar graphs are the average of triplicate transfections normalized to CAT activity. Error bars are \pm standard deviation.

tom). This result suggests that the specific effect of ( - ) Bay K 8644 on nAChR $\varepsilon$-subunit RNA (Fig. 1) likely results from a post-transcriptional regulation.

\section{DNA Sequences Mediating the Effects of Ryanodine Map to Those That Are Necessary for Activity-Dependent Regulation}

The above data suggest that calcium release from the SR can suppress nAChR gene expression. Because calcium release from the SR is an activitydependent process, and because the $\mathrm{nAChR}$ promoters are also regulated by muscle activity, it seemed reasonable to hypothesize that the same DNA elements mediating activity-dependent expression also mediated the response of these genes to ryanodine.

Three nAChR subunit gene promoters $(\alpha, \gamma$, and $\delta$ ) have been characterized in sufficient detail to identify DNA residues necessary for activity-dependent regulation [Fig. 6(A)]. The 116-bp $\alpha$-subunit
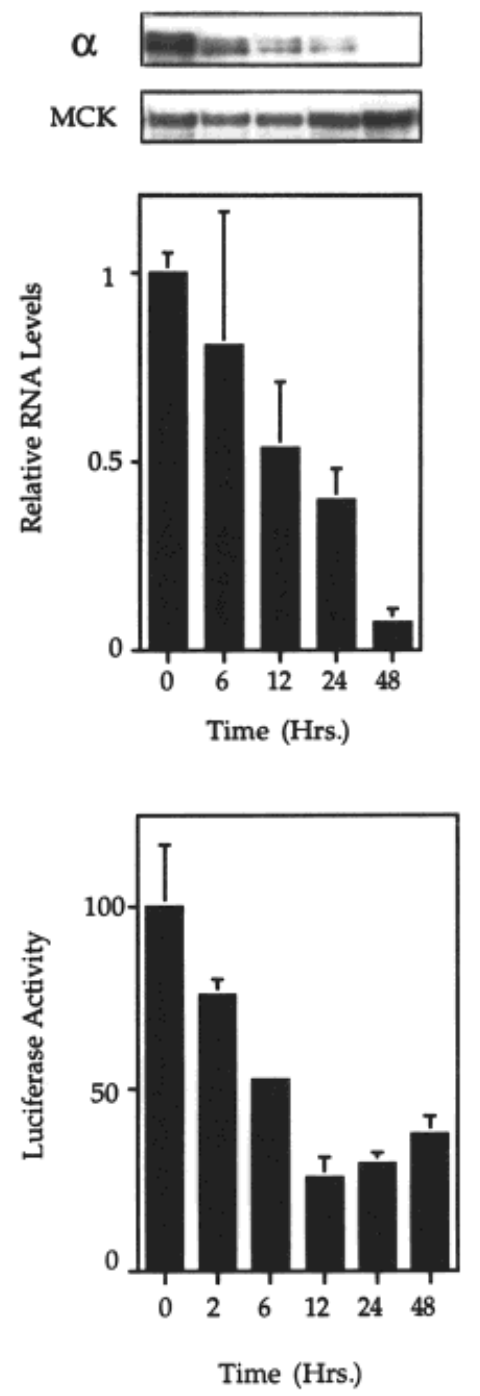

Figure 4 Time course of nAChR RNA and promoter activity changes in response to ryanodine. (Top) Primary myotubes were treated with $1.0 \mu M$ ryanodine for $0,6,12,24$, and $48 \mathrm{~h}$. Muscle creatine kinase (MCK) and the nAChR $\alpha$-subunit RNA $(\alpha)$ levels were determined by RNase protection assays (representative autoradiogram shown above) and quantitated by scanning densitometry. Relative RNA values are nAChR $\alpha$-subunit RNA levels normalized to MCK RNA levels. (Bottom) Primary muscle cultures were cotransfected with the 116-bp chick $\alpha$-promoter/luciferase construct and a CMVCAT vector (for normalization purposes) and treated with $1.0 \mu M$ ryanodine for for $2,6,12,24$, and $48 \mathrm{~h}$ prior to harvesting and assaying reporter gene expression. The normalized luciferase value for control $(0 \mathrm{~h})$ is 13,041 \pm 2201 light units. Bar graphs are the average of triplicate transfections normalized to CAT activity. Asterisks above histograms indicate statistical significance at $p<0.05$ using Student $t$ test. Error bars are \pm standard deviation. 


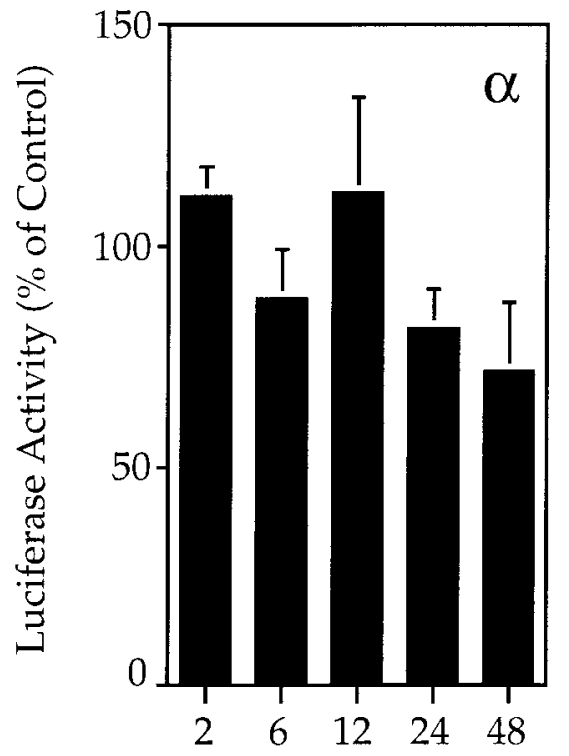

Time (h)

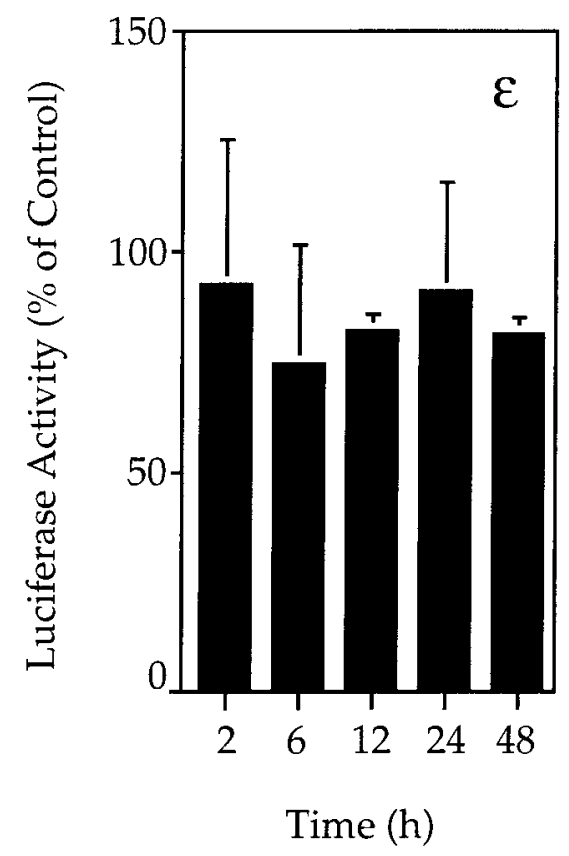

Figure 5 Effect of (-)Bay K 8644 on nAChR $\alpha$ - and $\varepsilon$-subunit promoter activity. The luciferase gene, placed under control of the 116-bp chick $\alpha$-promoter or the 5$\mathrm{kb} \varepsilon$-promoter, was transiently transfected into myotubes along with the CMVCAT vector (for normalization purposes). Cells were then treated with $30.0 \mu M(-)$ BayK 8644 or buffer for $2,6,12,24$, and $48 \mathrm{~h}$ prior to harvesting promoter contains two E boxes necessary for activity-dependent regulation in primary chick myotubes and the mouse C2C12 cell line (Bessereau et al., 1994; Su et al., 1995). Mutation of either E-box [Mp or Mb in Fig. 6(A)] partially influenced activity-dependent gene expression, while mutation of both sequences completely abrogated this regulation (Bessereau et al., 1994; Su et al., 1995). Here, we show that both E-boxes must also be mutated to block the suppressive effects of ryanodine [Fig. 6(B)].

We had previously identified a 46-bp region of the $\gamma$-subunit gene promoter (nucleotides -114 to -159) that is necessary for its suppression by muscle activity (Gilmour et al., 1995). A minimal $\gamma$ promoter construct, pX2BG76 [Fig. 6(A)], lacking residues -114 to -159 is not regulated by muscle activity. However, when nucleotides -114 to -159 are placed upstream of this minimal promoter (pX2BGE76) [Fig. 6(A)], activity-dependent expression is restored (Gilmour et al., 1995). Likewise, pX2BGE76 promoter activity is suppressed by ryanodine, while pX2BG76 is not [Fig. 6(B)].

Finally, we had also previously reported the identification of a 47-bp enhancer $(\delta-47 /-1)$ that is necessary and sufficient to mediate the effects of muscle activity on $\delta$-subunit gene expression (Walke et al., 1996). This enhancer appears to be composed of three elements (SV, Sp, and E), each of which when mutated completely abrogates regulated expression in response to muscle activity (Walke et al., 1996). Expression vectors were created in which the wild-type or mutant 47-bp enhancer were placed upstream of the minimal enkephalin (MEK) promoter (Walke et al., 1996) [Fig. 6(A)]. The MEK promoter is not regulated by calcium (Walke et al., 1994) or muscle activity (Walke et al., 1996). The wild-type construct ( $\delta$ $-47 /-1)$ showed approximately a $75 \%$ reduction in activity in response to ryanodine, while the various mutants $(\delta-47 /-1 \mathrm{SV}$ mut, Sp mut, and $\mathrm{E}$ mut) were insensitive to ryanodine [Fig. 6(B)].

We also tested these wild-type and mutated promoter constructs for responsiveness to thapsigargin. As reported for ryanodine, wild-type promoters were repressed by thapsigargin, while mutant promoters were not (L. Adams and D. Goldman, unpublished observation). Therefore, elements medi-

and assaying reporter gene expression. Bar graphs are the average of triplicate transfections normalized to CAT activity. Error bars are \pm standard deviation. 
ating $\mathrm{nAChR}$ promoter repression by calcium release from the SR map to those that mediate activity-dependent expression.

\section{The Effects of Ryanodine on nAChR Gene Expression Are Blocked by Dantrolene}

Dantrolene inhibits calcium release from the SR (Ellis and Carpenter, 1972; Nelson et al., 1996). We used this drug to determine whether we could suppress the effects of ryanodine on nAChR gene expression. If ryanodine mediates its effects on $\mathrm{nAChR}$ expression by stimulating calcium release from the SR, then dantrolene should reduce this effect. However, if ryanodine mediated its effects independently of calcium release from the SR, dantrolene might be observed to have little effect.

Indeed, in the presence of dantrolene, myotubes exhibited a dramatically reduced ryanodine response compared to myotubes that were not treated with dantrolene (Fig. 7). Increasing amounts of dantrolene blocked the ryanodine-dependent suppression of nAChR RNA and promoter activity in a dose-dependent manner up to approximately $75 \%$ of control (Fig. 7). In addition, dantrolene alone was able to modestly increase nAChR RNA and promoter activity by approximately $20 \%$ and $40 \%$, respectively. In contrast, use of the L-type calcium channel antagonist (+) Bay K 8644 in place of dantrolene in the above experiments had no effect on nAChR gene expression (L. Adams and D. Goldman, unpublished observation). These experiments, along with the use of other SR-acting drugs such as thapsigargin, support the idea that suppression of nAChR RNA and promoter activity by ryanodine is largely a result of calcium release from the SR. However, we cannot rule out the possibility, albeit remote, that dantrolene could increase nAChR RNA and promoter activity by another, unknown mechanism.

\section{DISCUSSION}

The major findings reported here are: (a) L-type channel agonist Bay K 8644 had no effect on nAChR promoter activity, yet specifically suppressed the nAChR $\varepsilon$-subunit RNA levels; (b) nAChR RNA levels and promoter activity are suppressed by treatment with drugs that have been demonstrated to release calcium from the SR; and, finally, (c) nAChR promoter sequences mediating this suppression map to those previously shown to mediate activity-dependent expression of these genes. Therefore, we propose that in rat, SR calcium is a source of cytoplasmic calcium that contributes to reduced nAChR gene expression in active compared to inactive muscle.

The observation that activation of ryanodine receptor calcium channels in the sarcoplasmic reticulum caused decreased $\mathrm{nAChR}$ gene transcription, while activation of sarcolemmal L-type calcium channels specifically affected $\varepsilon$-RNA expression post-transcriptionally, suggests that specific signaling cascades are linked to specific channel types. However, we have not ruled out the possibility that these two different calcium channels mediate their effects on $\mathrm{nAChR}$ gene expression by raising intracellular calcium to different levels. The idea of distinct signaling cascades being coupled to particular calcium channels is not new. For example, calcium influx through NMDA receptors and L-type calcium channels mediate their effects on c-fos promoter activity by activating distinct signaling pathways in neurons (Ghosh et al., 1994).

Therefore, we recognize the possibility that a specific source of intracellular calcium might play an important role in mediating activity-dependent gene expression. Our results are surprising in light of recent studies indicating that calcium flux through L-type channels, but not from SR stores, suppresses $\mathrm{nAChR}$ gene expression in chick and the mouse muscle cell line C2C12 (Huang and Schmidt, 1994; Huang et al., 1994). The reasons for this apparent discrepancy are not known. However, it is possible that the rat and chick nAChR genes respond to calcium-dependent signaling emanating from different calcium sources. In addition, it should be kept in mind that the $\mathrm{C} 2 \mathrm{C} 12$ cell line is a transformed muscle cell that may have acquired many changes leading to its transformed phenotype. Differences between this cell line and the primary rat muscle cultures used in this study may include signaling cascades and SR development (Grassi et al., 1994). In fact, the observation that ryanodine was unable to block depolarization-triggered calcium release from the SR and the partial effectiveness of dantrolene in $\mathrm{C} 2 \mathrm{C} 12$ cells (Huang et al., 1994) are consistent with this latter possibility.

RNase protection and transient transfection assays revealed a relatively robust effect of ryanodine and thapsigargin on $\mathrm{nAChR}$ gene expression (Figs. 1, 4, and 6). Our observation that in addition to decreasing $\alpha-, \gamma-$, and $\delta$-RNA and promoter activity ryanodine also suppressed $\varepsilon$-promoter activity (69\% reduction) is consistent with transgenic studies showing the $\varepsilon$-promoter is regulated by muscle 
A

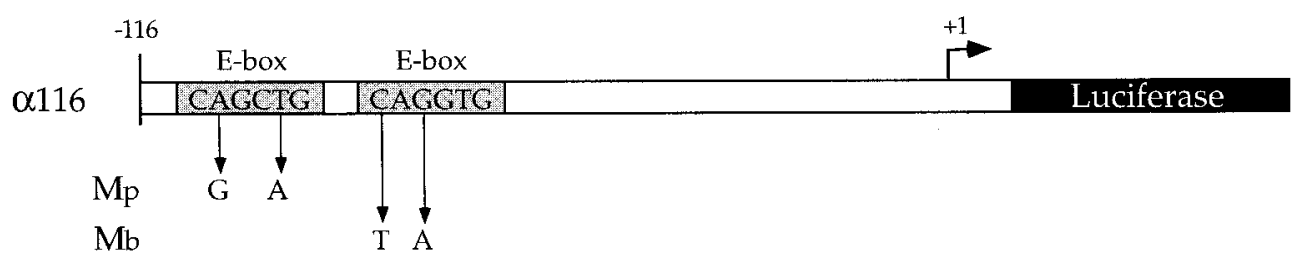

$\gamma$ pX2 BG169

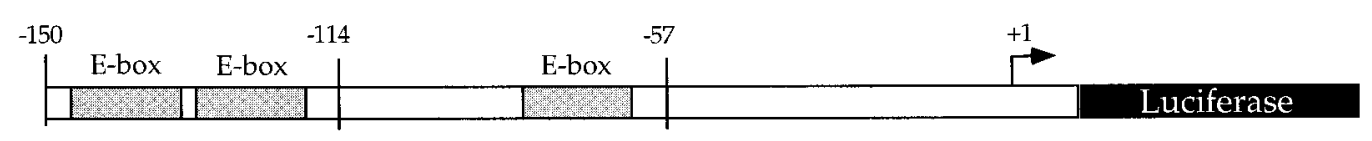
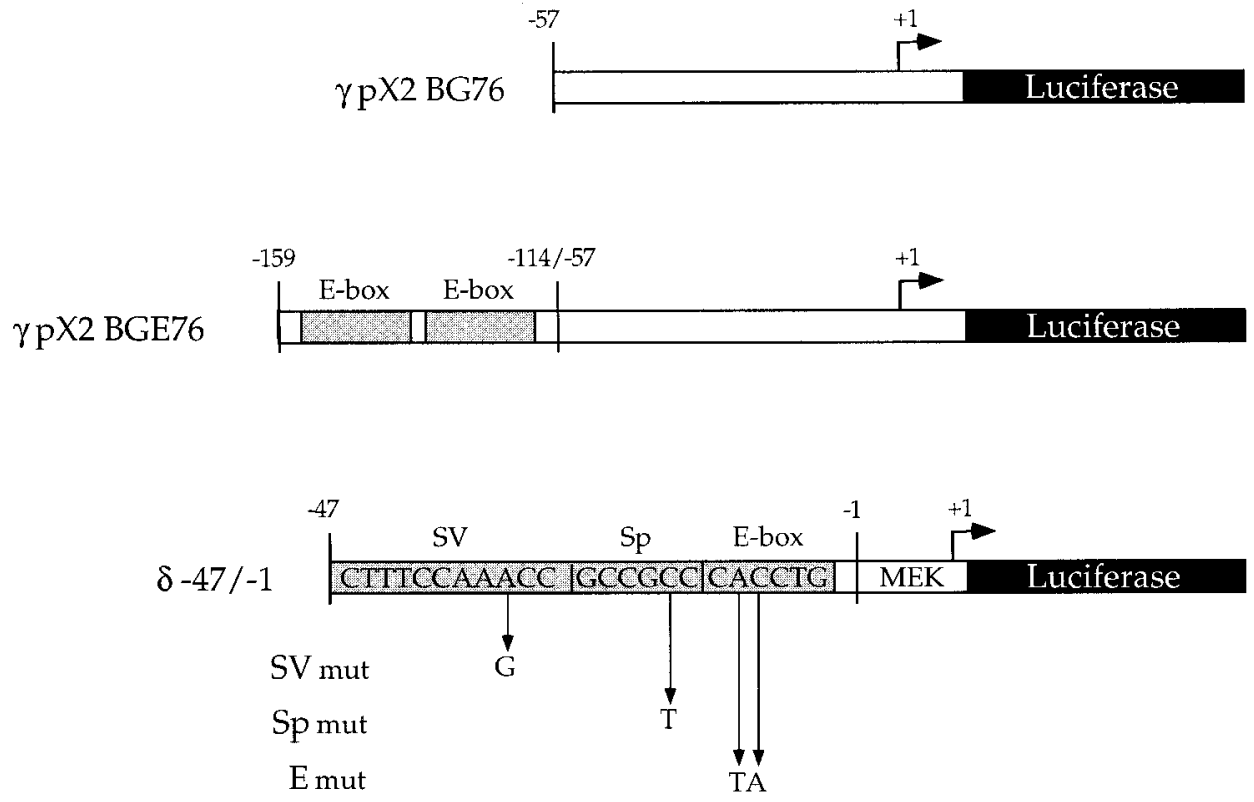

Figure 6 nAChR promoter elements mediating the effects of ryanodine map to sequences that are necessary for activity-dependent gene expression. (A) Schematic representation of $\alpha-, \gamma$-, and $\delta$-promoter expression vectors used in this study. $\alpha 116$ contains the 116 -bp chick $\alpha$-promoter driving luciferase expression. DNA sequence changes in mutants $\mathrm{Mp}$ and $\mathrm{Mb}$ are indicated with arrows (Piette et al., 1990). $\gamma$ pX2BG169 contains a 150-bp $\gamma$-promoter driving luciferase expression. $\gamma \mathrm{pX} 2 \mathrm{BG} 76$ is a minimal 57-bp $\gamma$-promoter driving luciferase expression. $\gamma$ pP2BGE76 is a fusion construct in which $\gamma$-promoter sequences -159 to -114 were ligated to $\gamma$ pX2BG76 (Gilmour et al., 1995). $\delta-47 /-1$ contains the $\delta$-promoter muscle-specific, activitydependent enhancer upstream of the minimal enkephalin (MEK) promoter. Nucleotide changes in mutants SV, Sp, and E are indicated by arrows (see Walke et al., 1996, for details). (B) The luciferase gene, placed under control of wild-type or mutated fragments of the nAChR $\alpha-, \gamma-$, and $\delta$-subunit gene promoters were transiently transfected into myotubes along with the CMVCAT vector (for normalization purposes). Cells were then treated with ryanodine ( 1 $\mu M$ ) or buffer for $48 \mathrm{~h}$ prior to harvesting for luciferase and CAT activity. For each construct, luciferase values represent averages from three different dishes of myotubes and are reported as a percentage of control cells treated with buffer $(100 \%)$. The normalized luciferase values for controls, expressed as light units are: $\alpha-116=150,477 \pm 9008 ; \alpha-116 \mathrm{Mb}=15,270 \pm 137$; $\alpha-116 \mathrm{Mp}=33,020 \pm 4445 ; \alpha-116 \mathrm{Mbp}=6816 \pm 2165 ; \gamma-\mathrm{pXP} 2 \mathrm{BG} 169=8984 \pm 3164 ;$ $\gamma$-pXP2BGE76 $=119 \pm 20 ; \gamma$-pXP2BGE76 $=20 \pm 4 ; \delta$-47/ $-1=15,636 \pm 2236 ; \delta$-47/ -1 $\mathrm{SV}$ mut $=282 \pm 27 ; \delta-47 /-1 \mathrm{Sp}$ mut $=249 \pm 18 ; \delta-47 /-1 \mathrm{E}$ mut $=328 \pm 24$. Error bars are \pm standard deviation. 

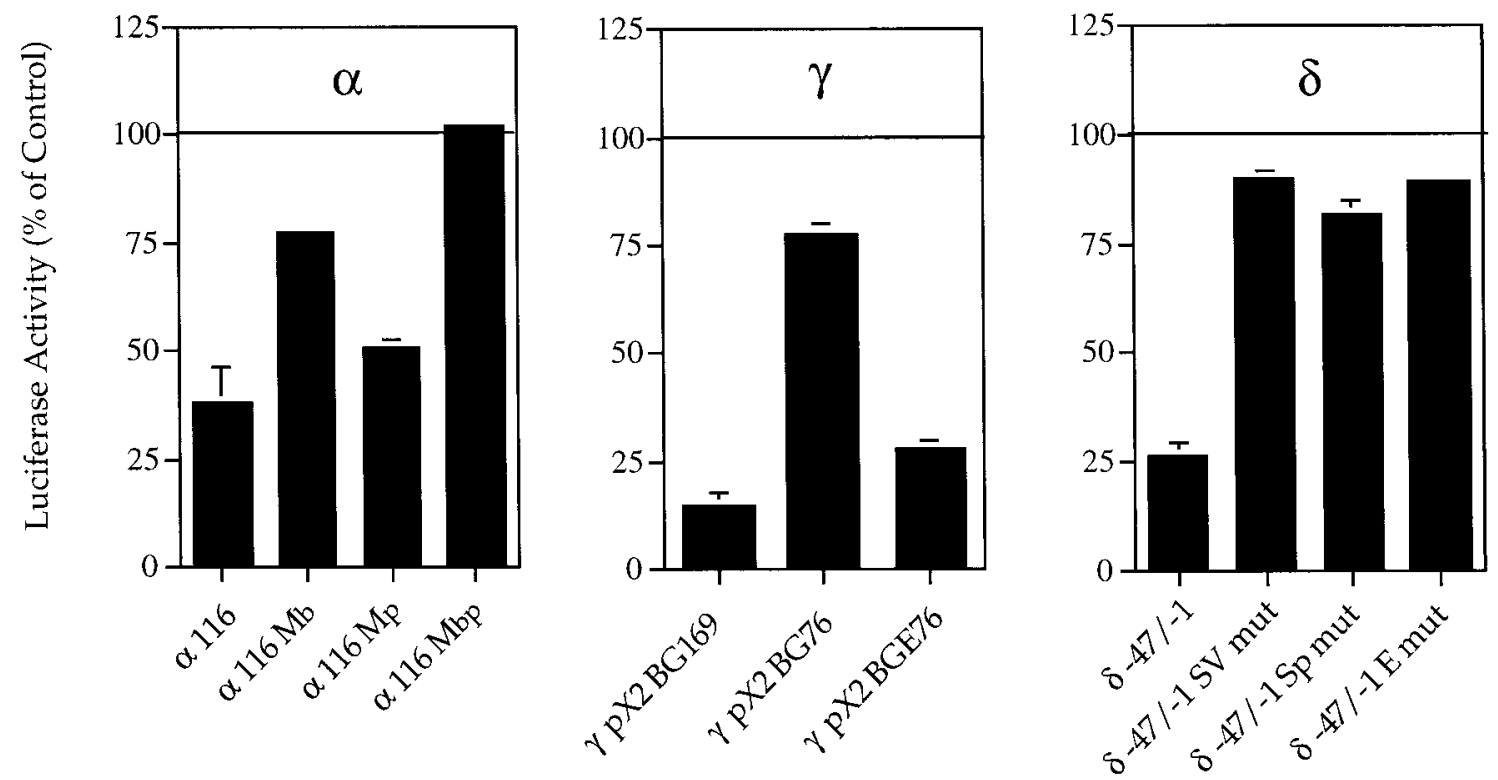

Figure 6 (Continued) activity in vivo (Gundersen, 1993). However, because this promoter directs expression to the synapse and is less responsive to muscle activity than the other nAChR promoters, we suggest that other regulatory cascades may also contribute to $\varepsilon$-promoter activity and RNA expression profiles. Indeed, it has recently been shown that the $\varepsilon$-gene is regulated by a Ras-dependent signaling cascade (Tansey et al., 1996; Si et al., 1996).

In contrast to the relatively robust effect of ryanodine on nAChR RNA levels, (-)Bay K 8644 was more restricted in its effects, causing a large decrease in $\varepsilon$-RNA with somewhat lesser of an effect on the $\alpha$ - and $\delta$-RNAs (Fig. 1). This may indicate that these latter RNAs are also regulated by a calcium influx-dependent signaling pathway. However, their responsiveness to this pathway may be less than the $\varepsilon$-RNA owing to differences in their DNA/RNA calcium-responsive elements. Alternatively, if calcium influx is large enough, it might begin to impinge upon signaling molecules that normally respond to calcium changes occurring in close proximity to the SR, modestly activating its signaling cascade and resulting in a relatively modest RNA change. Similar arguments could also be applied to the relatively modest effect of ryanodine on $\varepsilon$-RNA expression.
Finally, the modest effect of calcium influx on $\mathrm{nAChR} \alpha$ - and $\delta$-RNAs may reflect a change in promoter activity that is compensated by an opposing change in RNA stability. This does not appear to be likely, since the $\alpha$-promoter was repressed by only $20-25 \%$ following $24-48 \mathrm{~h}$ of drug treatment, while the 550 -bp $\delta$-promoter, like the $\varepsilon$-promoter, was not regulated by (-)Bay K 8644 (data not shown). These data suggest a post-transcriptional mechanism of regulation of these RNAs by calcium influx. However, we cannot rule out the possibility that elements mediating a response to $(-)$ Bay $\mathrm{K}$ 8644 are not included in our 550-bp $\delta$ - and $5 \mathrm{~kb} \varepsilon$ promoter constructs.

Might treating muscle cells with calcium-perturbing agents for periods extending beyond a few hours cause such a large or long-lasting change in intracellular calcium that it results in nonspecific effects due to perturbation of multiple regulatory events? We do not think so, because our RNase protection and transient transfection assays argue in favor of specificity. First, RNase protection assays showed only drugs (ryanodine and thapsigargin), stimulating release of calcium from the SR suppress nAChR gene expression, while the L-type calcium channel activator specifically affected the adult-type specific $\varepsilon$-RNA (Fig. 1). Second, we showed that 

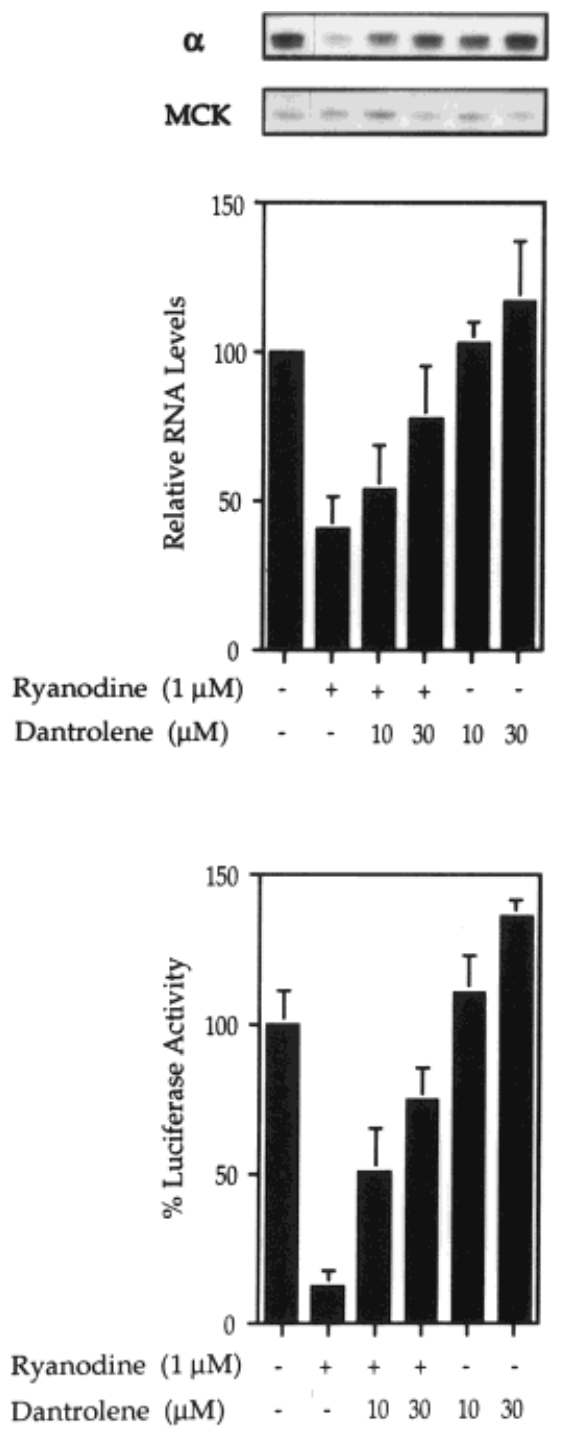

Figure 7 The effects of ryanodine on nAChR RNA and promoter activity are inhibited by dantrolene. (Top) Primary myotubes were treated with $1.0 \mu M$ ryanodine and/or 10 and $30 \mu M$ dantrolene for $48 \mathrm{~h}$. Muscle creatine kinase (MCK) and the nAChR $\alpha$-subunit RNA $(\alpha)$ levels were determined by RNase protection assays (representative autoradiogram shown at top) and quantitated by scanning densitometry (top). Relative RNA values are nAChR $\alpha$-subunit RNA levels normalized to MCK RNA levels. (Bottom) Primary muscle cultures were cotransfected with the chick 116bp $\alpha$-promoter/luciferase construct and CMVCAT (for normalization purposes). Following transfection, cells were treated with $1.0 \mu M$ ryanodine and/or 10 and 30 $\mu M$ dantrolene for $48 \mathrm{~h}$ prior to harvesting and assaying reporter gene expression. Bar graphs are the average of triplicate transfections. Percent luciferase activity represents normalized luciferase values reported as a percentage of the control cell value. Error bars are \pm standard deviation. there is a characteristic ryanodine dose response that follows the effect of ryanodine on the ryanodine receptor (Meissner, 1968; Buck et al., 1992) (Figs. 2 and 3 ). Third, we were able to attenuate the effects of ryanodine on nAChR RNA and promoter activity by adding dantrolene (Fig. 7), which inhibits calcium release from the SR. Fourth, time-course assays suggest the effect of ryanodine on $\mathrm{nAChR}$ promoter activity is already observable by $6 \mathrm{~h}$ after drug treatment (Fig. 4, bottom). All these results argue for a specific action of ryanodine on $\mathrm{nAChR}$ gene expression via its effect on calcium release from the SR.

Based on the results described above, and because calcium is released from the SR during muscle contraction, we propose that calcium release from the SR participates in coupling muscle depolarization to $\mathrm{nAChR}$ gene expression in rat. To support this contention, we determined if the same DNA regulatory elements mediating $\mathrm{nAChR}$ promoter activity in response to muscle depolarization also mediate the effects of ryanodine and thapsigargin. Indeed, for the $\alpha-\gamma-$, and $\delta$-subunit gene promoters, where elements mediating activity-dependent expression were mapped, these same activity-dependent sequences were also necessary for regulation by ryanodine and thapsigargin (Fig. 6; data shown only for ryanodine).

However, it should be noted that the 116-bp $\alpha$ promoter construct that was used in the above promoter study has been shown to be regulated by muscle activity in a muscle-specific fashion (Merlie et al., 1994). In this case, transgenic animals harboring a 111-bp $\alpha$-promoter driving CAT expression showed activity-dependent expression in tibialis and extensor digitorum longus muscle but no expression in the soleus muscle. It was concluded that the lack of activity-dependent expression in soleus muscle was secondary to the more severe loss of expression in this muscle (Merlie et al., 1994). In addition, this same promoter, when placed in an adenovirus vector, was suppressed by muscle activity in cell culture but was unresponsive to muscle activity in vivo (Bessereau et al., 1994). Because the muscles assayed in this latter study were not reported, it is difficult to determine if this lack of an activitydependent response in vivo was a result of the type of muscle assayed. Nonetheless the $\alpha$ - and $\delta$-promoters used in this study clearly contain elements mediating activity-dependent gene expression in vivo (Merlie et al., 1994; Tang et al., 1994; Walke et al., 1996).

Might calcium influx also contribute to activitydependent expression of $\mathrm{nAChR}$ genes in rat skele- 
tal muscle? This is a difficult question to answer at this point. We clearly see some relatively modest regulation of the nAChR RNAs by calcium influx, and this may contribute to activity-dependent suppression of these genes in vivo. However, we have not been able to map this response to the $\mathrm{nAChR}$ promoter elements already identified as participating in activity-dependent control of gene expression. One possibility is that promoter elements responding to calcium influx are not contained within the promoter fragments used in this study.

Finally, if the above results and conclusions are to be applied to normal skeletal muscle, we have to consider whether one can use primary muscle cells in tissue culture to study mechanisms participating in activity-dependent gene expression. We and many others in this field think so. This is illustrated by a large body of work in cell culture that has identified genes regulated by muscle activity (Klarsfeld and Changeux, 1985; Chahine et al., 1993), and the DNA elements (Chahine et al., 1992; Dutton et al., 1993; Bessereau et al., 1994; Gilmour et al., 1995) and signaling cascades (Klarsfeld et al., 1989; Laufer et al., 1991; Chahine et al., 1993; Huang et al., 1994; Mendelzon et al., 1994) that appear to be responsible for this regulation. It is interesting to note that in the chick system, primary muscle cultures were the first to be used to show protein synthesis is required for the induction of $\mathrm{nAChR}$ gene expression following block of muscle activity with tetrodotoxin (Duclert et al., 1990) and were instrumental in identifying protein kinase $\mathrm{C}$ as a potential mediator of activity-dependent suppression of nAChR gene expression (Fontaine et al., 1987; Klarsfeld et al., 1989), both of which were subsequently shown to play an important role mediating activity-dependent control of gene expression in vivo (Tsay et al., 1990; Huang et al., 1992). Likewise, cell culture systems have been instrumental in characterizing promoter elements mediating activity-dependent control of gene expression (Dutton et al., 1993; Chahine et al., 1992; Laufer et al., 1991). Therefore, we believe that the use of a cell culture system can provide many valuable insights into the mechanisms controlling nAChR gene expression in vivo. However, one must be cautious in extrapolating in vitro results to in vivo situations. Ultimately, the role of the SR calcium in mediating rat muscle activity-dependent control of nAChR gene expression in vivo must be examined. However, these are extremely difficult experiments to carry out. Nonetheless, our data suggest that these experiments will be worth pursuing.
This work was supported by grants from the National Institutes of Health and Muscular Dystrophy Association (awarded to DG). The authors thank Dr. P. Gardner for providing the mouse $\gamma$-promoter clones, Dr. J. P. Merlie for providing the chick $\alpha$-promoter, W. Walke and M. Sapru for technical assistance, K. Williams and N. Goburdhun for their help in DNA preparations and cell culture, and Dr. R. Hume for critical reading of the manuscript.

\section{REFERENCES}

Altiok, N., Bessereau, J. L., and Changeux, J. P. (1995). Erb B3 and ErbB2/neu mediate the effect of heregulin on acetylcholine receptor gene expression in muscle: differential expression at the endplate. $E M B O$ J. 14:4258-4266.

Bessereau, J.-L., Stratford-Perricaudet, L. D., Piette, J., Poupon, C. L., and Changeux, J.-P. (1994). In vivo and in vitro analysis of electrical activity-dependent expression of muscle acetylcholine receptor genes using adenovirus. Proc. Natl. Acad. Sci. USA 91:1304-1308.

Birnbaum, M., Reis, M. A., and Shainberg, A. (1980). Role of calcium in the regulation of acetylcholine receptor synthesis in cultured muscle cells. Pflugers Arch. 385:37-43.

Brasier, A. R., Tate, J. E., and Habener, J. F. (1989). Optimized use of the firefly assay as a reporter gene in mammalian cell lines. Biotechniques 7:1116-1122.

Buck, E., Zimanyi, I., Abramson, J. J., and Pessah, I. N. (1992). Ryanodine stabilizes multiple conformational states of the skeletal muscle calcium release channel. J. Biol. Chem. 267:23560-23567.

Chahine, K. C., Baracchini, E., and Goldman, D. (1993). Coupling muscle electrical activity to gene expression via a cAMP-dependent second messenger system. J. Biol. Chem. 268:2893-2898.

Chahine, K. C., Walke, W., and Goldman, D. (1992). A 102 base pair sequence of the nicotinic acetylcholine receptor delta subunit gene confers regulation by muscle electrical activity. Development 115:213-219.

Chirgwin, J. M., Przybyla, A. E., MacDonald, R. J., and RUTTER, W. J. (1979). Isolation of biologically active ribonucleic acid from sources enriched in ribonuclease. Biochemistry 18:5294-5299.

Delbono, O. and Chu, A. (1995). $\mathrm{Ca}^{2+}$ release channels in rat denervated skeletal muscles. Exp. Physiol. 80:561-574.

Duclert, A., Piette, J., and Changeux, J. P. (1990). Induction of acetylcholine receptor a-subunit gene expression in chicken myotubes by blocking electrical activity requires ongoing protein synthesis. Proc. Natl. Acad. Sci. USA 87:1391-1395.

Dutton, E. K., Simon, A. M., and Burden, S. J. (1993). Electrical activity-dependent regulation of the acetylcholine receptor d-subunit gene, Myo D and myogenin 
in primary myotubes. Proc. Natl. Acad. Sci. USA 90:2040-2044.

Ellis, K. O. and CARPEnTER, J. F. (1972). Studies on the mechanism of action of dantrolene sodium, a skeletal muscle relaxant. Naunyn Schmied. Arch. Pharmacol. 275:83-94.

Falls, D., Rosen, K., Corfas, G., Lane, W., and FischBACH, G. (1993). ARIA, a protein that stimulates acetylcholine receptor synthesis, is a member of the neu ligand family. Cell 72:801-815.

Fontaine, B., Klarsfeld, A., and Changeux, J. P. (1987). Calcitonin gene-related peptide and muscle activity regulate acetylcholine receptor $\alpha$-subunit mRNA levels by distinct intracellular pathways. J. Cell Biol. 105:1337-1342.

Forrest, J. W., Mills, R. G., Bray, J. J., and Hubbard, J. I. (1981). Calcium-dependent regulation of the membrane potential and extrajunctional acetylcholine receptors of rat skeletal muscle. Neuroscience 6:741749.

Ghosh, A., Ginty, D. D., Bading, H., and GreenberG, M. E. (1994). Calcium regulation of gene expression in neuronal cells. J. Neurobiol. 25:294-303.

Gilmour, B. P., Goldman, D., Chahine, K. C., and GARDNER, P. G. (1995). Electrical activity suppresses nicotinic acetylcholine receptor $\gamma$ subunit promoter activity. Dev. Biol. 168:416-428.

Goldman, D., Brenner, H. R., and Heinemann, S. (1988). Acetycholine receptor $\alpha, \beta, \gamma$, and $\delta$ subunit mRNA levels are regulated by muscle activity. Neuron 1:329-333.

Grassi, F., Fucile, S., and Eusebi, F. (1994). $\mathrm{Ca}^{2+}$ signalling pathways activated by acetylcholine in mouse C2C12 myotubes. Pflugers Arch. 428:340-345.

Gundersen, K., Sanes, J. R., and Merlie, J. P. (1993). Neural regulation of muscle acetycholine receptor $\varepsilon$ and $\alpha$-subunit gene promoters in transgenic mice. $J$. Cell Biol. 123:1535-1544.

Hall, A. W., and SANes, J. R. (1993). Synaptic structure and development: the neuromuscular junction. Cell 10(Suppl.): :99-120.

Huang, C.-F., Flucher, B., Schmidt, M., Stroud, S. K., and SCHMIDT, J. (1994). Depolarization-transcription signals in skeletal muscle use calcium flux through $\mathrm{L}$ channels, but bypass the sarcoplasmic reticulum. Neuron 13:167-177.

Huang, C.-F. and Schmidt, J. (1994). Calcium influx blocks the skeletal muscle acetylcholine receptor $\alpha$ subunit gene in vivo. FEBS Lett. 338:277-280.

Huang, C.-F., Tong, J., and Schmidt, J. (1992). Protein kinase $\mathrm{C}$ couples membrane excitation to acetylcholine receptor gene inactivation in chick skeletal muscle. Neuron 9:671-678.

Klarsfeld, A., Bessereau, J.-L., Salmon, A.-M., Triller, A., Babinet, C., and Changeux, J.-P. (1991). An acetylcholine receptor $\alpha$-subunit promoter conferring preferential synaptic expression in muscle of transgenic mice. EMBO J. 10:625-632.
Klarsfeld, A. and Changeux, J. P. (1985). Activity regulates the levels of acetylcholine receptor $\alpha$-subunit mRNA in cultured chicken myotubes. Proc. Natl. Acad. Sci. USA 82:4558-4562.

Laufer, R., Klarsfeld, A., and Changeux, J. P. (1991). Phorbol esters inhibit the activity of the chicken acetylcholine receptor a-subunit gene promoter. Eur. J. Biochem. 202:813-818.

Klarsfeld, A., Laufer, R., Fontaine, B., DevillersThiery, A., Dubreuil, C., and Changeux, J.-P. (1989). Regulation of muscle AChR $\alpha$-subunit gene expression by electrical activity: involvement of protein kinase $\mathrm{C}$ and $\mathrm{Ca}^{2+}$. Neuron 2:1229-1236.

MeIsSNER, G. (1968). Ryanodine activation and inhibition of the $\mathrm{Ca}^{2+}$ release channel of sarcoplasmic reticulum. J. Biol. Chem. 261:6300-6306.

Mendelzon, D., Changeux, J. P., and Nghiem, H.-O. (1994). Phosphorylation of myogenin in chick myotubes: regulation by electrical activity and by protein kinase C: Implications for acetylcholine receptor gene expression. Biochemistry 33:2568-2575.

Merlie, J. P., and Kornhauser, J. M. (1989). Neural regulation of gene expression by an acetylcholine receptor promoter in muscle of transgenic mice. Neuron 2:1295-1300.

Merlie, J. P., Mudd, J., Cheng, T.-C., and Olson, E. N. (1994). Myogenin and acetylcholine receptor $\alpha$ gene promoters mediate transcriptional regulation in response to motor innervation. J. Biol. Chem. 269:24612467.

Moscoso, L. M., Chu, G. C., Gautam, M., Noakes, P. G., Merlie, J. P., and Sanes, J. R. (1995). Synapse associated expression of an acetylcholine receptor-inducing protein, ARIA/heregulin, and its putative receptors, erbB2 and erbB3, in developing mammalian muscle. Dev. Biol. 172:158-169.

Nelson, T. E., Marina, L., Gisele, Z.-S., and Sudo, R. T. (1996). Dantrolene sodium can increase or attenuate activity of skeletal muscle ryanodine receptor calcium release channel. Anesthesiology 84:1368-1378.

Neumann, J. R., Morency, C. A., and Russian, K. O. (1987). A novel rapid assay for chloramphenicol acetyltransferase gene expression. Biotechniques 5:444447.

NoRDEEN, S. K. (1988). Luciferase reporter gene vectors for analysis of promoters and enhancers. Biotechniques 6:454-457.

Pezzementi, L., and Schmidt, J. (1981). Ryanodine alters the rate of acetylcholine receptor synthesis in chick skeletal muscle cell cultures. J. Biol. Chem. 256: $12651-12654$.

Piette, J., Bessereau, J.-L., Huchet, M., and ChangEUX, J.-P. (1990). Two adjacent MyoD1-binding sites regulate expression of the acetylcholine receptor $\alpha$ subunit gene. Nature 345:353-355.

Reuter, H., Porzig, H., Kokubun, H. S., and Prodhom, B. (1985). 1,4-Dihydropyridines as tools in the study of $\mathrm{Ca}^{2+}$ channels. Trends Neurosci. 8:396-400. 
Saccomanno, C. F., Bordonaro, M., Chen, J. S., and Nordstrom, J. L. (1992). A faster ribonuclease protection assay. Biotechniques. 13:846-850.

SAGARA, Y. and INESI, G. (1991). Inhibition of the sarcoplasmic reticulum $\mathrm{Ca}^{2+}$ transport ATPase by thapsigargin at subnanomolar concentrations. J. Biol. Chem. 266: $13503-13506$.

Sandrock, A. W. JR., Dryer, S. E., Rosen, K. M., GoZani, S. N., Kramer, R., Theill, L. E., and FischBACH, G. D. (1997). Maintenance of acetylcholine receptor number by neuregulins at the neuromuscular junction in vivo. Science 276:599-603.

SAnes, J. R., Johnson, Y. R., Kotzbauer, P. T., Mudd, J., Hanley, T., Martinou, J.-C., and Merlie, J. P. (1991). Selective expression of an acetylcholine receptor-lacZ transgene in synaptic nuclei of adult muscle fibers. Development 113:1181-1191.

Si, J., LuO, Z., and MEI, L. (1996). Induction of acetylcholine receptor gene expression by ARIA requires activation of mitogen-activated protein kinase. J. Biol. Chem. 271:19752-19759.

Simon, A. M., Hoppe, P., and Burden, S. J. (1992). Spatial restriction of AChR gene expression to subsynaptic nuclei. Development 114:545-553.

Smilowitz, H., Smart, E., Bowik, C., and Chang, R. J. (1988). Regulation of the number of $\alpha$-bungarotoxin binding sites in cultured chick myotubes by a 1,4-dihydropyridine calcium channel antagonist. J. Neurosci. Res. 19:321-325.
Su, C.-T., Huang, C.-F., and Schmidt, J. (1995). The depolarization response element in acetylcholine receptor genes is a dual-function E-box. FEBS Lett. 366: $131-136$.

TAnG, J., Jo, S. A., and Burden, S. J. (1994). Separate pathways for synapse-specific and electrical activitydependent gene expression in skeletal muscle. Development 120:1799-1804.

Tansey, M. G., Chu, G. C., and Merlie, J. P. (1996). ARIA/HRG regulates AChR $\varepsilon$ subunit gene expression at the neuromuscular synapse via activation of phosphatidylinositol. J. Cell Biol. 134:465-476.

Tsay, H.-J., Neville, C. M., and SchmidT, J. (1990). Protein synthesis is required for the denervation-triggered activation of acetylcholine receptor genes. FEBS Lett. 274:69-72.

Walke, W., Staple, J., Adams, L., Gnegy, M., ChahINE, K., and GoldMAN, D. (1994). Calcium-dependent regulation of rat and chick muscle nicotinic acetylcholine receptor (nAChR) gene expression. J. Biol. Chem. 269: $19447-19456$.

Walke, W., XIAO, G., and Goldman, D. (1996). Identification and characterization of a 47 base pair activitydependent enhancer of the rat nicotinic acetylcholine receptor delta-subunit promoter. J. Neurosci. 16:36413651.

Zhu, X. J., Lai, C., Thomas, S., and Burden, S. J. (1995). Neuregulin receptors, erbB3 and erbB4 are localized at neuromuscular synapses. EMBO J. 14:5842-5848. 